\title{
Estudos de mucoadesão no trato gastrointestinal para o aumento da biodisponibilidade oral de fármacos
}

\author{
Felipe Oliveira Varum ${ }^{1,2}$, Abdul Waseh Basit² ${ }^{2}$ João Sousa ${ }^{1}$, Francisco Veiga ${ }^{1 *}$ \\ ${ }^{1}$ Faculdade de Farmácia, Universidade de Coimbra, ${ }^{2}$ Faculdade de Farmácia, Universidade de Londres
}

*Correspondência:

F. Veiga

Faculdade de Farmácia de Coimbra

Rua do Norte, 3000

Coimbra - Portugal

E-mail: fveiga@ci.uc.pt
A biodisponibilidade oral de muitos fármacos é limitada pelo tempo de residência das formas farmacêuticas ao longo do trato gastrointestinal. A mucoadesão tem sido proposta como forma de prolongar o tempo de residência em determinada zona, contribuindo para o aumento do efeito terapêtico dos fármacos. O estômago e o intestino delgado têm sido preferencialmente os alvos de estudo da mucoadesão, tendo sido observados resultados promissores em ensaios in vitro. Contudo, alguns ensaios em humanos, usando a técnica de $\gamma$-cintigrafia, têm revelado o insucesso da mucoadesão como forma de aumentar o tempo de contacto de formulações no trato gastrointestinal superior. A falta de correlação in vitro/in vivo pode ser atribuída à complexidade do trato gastrointestinal humano. Muitos dos modelos in vitro reproduzem apenas em parte as condições observadas in vivo. Outros fatores, tais como a motilidade, o pH, a espessura e a taxa de renovação de muco, presença de enzimas e alimentos, não têm sido simulados em ensaios in vitro. A taxa de renovação do muco, a sensibilidade aos estímulos secretores e a motilidade são mais baixas no cólon que no estômago e intestino delgado. Portanto, a mucoadesão no cólon poderá constituir um conceito mais bem sucedido. Contudo, são necessários mais estudos quer em modelos animais quer em humanos para avaliar o seu verdadeiro potencial. Além disso, são necessários estudos de farmacocinética para determinar a libertação e posterior absorção do fármaco a partir do sistema mucoadesivo.
Unitermos

- Fármacos/

biodisponibilidade oral

- Mucoadesão/ estudo in vitro

e in vivo

- Trato gastrointestinal/ estudo da mucoadesão

- Fármacos/absorção

\section{INTRODUÇÃO}

A administração oral de fármacos constitui a primeira escolha no desenvolvimento de formas farmacêuticas, devido à facilidade de administração e melhor adesão à terapêutica por parte do doente. Contudo, a administração oral envolve uma grande complexidade na interpretação de três elementos-chave: o fármaco, a forma farmacêutica e o sistema gastrointestinal (Wilding, 2000). Alguns fármacos são rapidamente absorvidos no estômago ou intestino delgado, podendo ser formulados em formas farmacêuticas de libertação imediata. Porém, muitos fármacos apresentam 
efeito subterapêutico ou um perfil indesejado de efeitos laterais quando formulados neste tipo de formas farmacêuticas. Assim, estes fármacos devem ser formulados em formas farmacêuticas de libertação modificada, quer por libertação prolongada, quer por libertação retardada (Kendall, Basit, 2006). As formas farmacêuticas de libertação prolongada permitem manter uma concentração sistémica de fármaco dentro da janela terapêutica por um longo período de tempo, permitindo assim reduzir o número de administrações. Porém, a performance destes sistemas está condicionada pelo trânsito através do trato gastrointestinal, o qual é muito variável, particularmente através do estômago e cólon (Wilding, 1995).

Muitos investigadores têm-se debruçado sobre a mucoadesão de formas farmacêuticas no trato gastrointestinal como forma de aumentar o tempo de residência numa dada zona, proporcionando aumento da absorção sistêmica ou atuação tópica (Park, Robinson, 1984; Ch'ng et al., 1985). A eficácia de um sistema mucoadesivo passa não só pela sua capacidade de aderir à mucosa gastrointestinal durante um longo período de tempo, mas também pela capacidade de libertar o fármaco nessa zona.

O objetivo deste trabalho é fazer uma abordagem do conceito de mucoadesão no que diz respeito ao seu fundamento, fatores intervenientes e potenciais vantagens na administração oral de formas farmacêuticas. A mucoadesão em diferentes zonas do trato gastrointestinal irá ser abordada em termos dos trabalhos realizados, métodos e modelos usados, potenciais vantagens e limitações, dando especial relevo à correlação entre os resultados obtidos em modelos animais e em humanos.

\section{TEMPO DE RESIDÊNCIA DAS FORMAS FARMACÊUTICAS NO TRATO GASTROINTESTINAL}

O tempo de residência das formas farmacêuticas no trato gastrointestinal condiciona largamente a desintegração, dissolução e posterior absorção de um dado fármaco veiculado através de formas farmacêuticas sólidas. O tempo de residência é distinto entre formas farmacêuticas unitárias (comprimidos e cápsulas) e multiunitárias (pellets e micropartículas), especialmente em nível do esvaziamento gástrico e trânsito através do cólon.

O tempo necessário para que uma dada forma farmacêutica passe através do esôfago e chegue ao estômago tem sido estimado em 10-14 segundos, podendo ser mais prolongado nos casos em que estas ficam alojadas na mucosa. O trânsito nesta zona é afetado pela postura e pelo volume de água ingerido com a forma farmacêutica, sendo que para menores volumes de água e postura horizontal o trânsito é mais lento (Batchelor, 2005).

As soluções e sistemas multiunitários são continuamente drenados do estômago mesmo na presença de alimentos enquanto que os sistemas unitários sofrem esvaziamento gástrico durante as contrações mais vigorosas. Se administrados após uma refeição, os sistemas unitários abandonam o estômago após os alimentos (Devereux et al., 1990; Tuleu et al., 1999; Wilding, 2000; Kendall, Basit, 2006).

O trânsito de formas farmacêuticas através do intestino delgado tem sido referido frequentemente como sendo em média 3-4 $( \pm 1)$ horas, contudo a variabilidade intra e interindividual é significativa (Coupe et al., 1991; Wilding, 1995; Tuleu et al., 2002). Além disso, parece ser independente do estado de jejum, tipo de forma farmacêutica, idade, ou situações patológicas (Follonier, Doelker, 1992; Wilding et al., 2001). Antes de entrarem no cólon, as formas farmacêuticas são reagrupadas na junção ileo-cecal. A junção ileo-cecal funciona como uma válvula entre o intestino delgado e o cólon, sendo o trânsito nesta zona independente do tamanho da forma farmacêutica (Adkin et al., 1993; Wilding, 2000). No cólon, o trânsito de formas farmacêuticas apresenta grande variabilidade inter e intraindividual, podendo oscilar entre 20 e 40 horas (Hardy, 1989). Os sistemas unitários têm apresentado um trânsito mais rápido no cólon que os sistemas multiunitários e soluções, talvez pelo fato de os primeiros serem reconhecidos como material não-digerível, ao contrário dos segundos, que permanecem no cólon durante um período mais longo (Adkin et al., 1993; Wilding, 2000). Têm sido referidos tempos de trânsito no cólon proximal de 5 horas para cápsulas e comprimidos enquanto que soluções e sistemas multiunitários têm registado tempos totais de residência no cólon de 30-40 horas (Hardy, 1989; Follonier, Doelker, 1992).

\section{O MUCO COMO REVESTIMENTO DA MUCOSA GASTROINTESTINAL}

A mucosa gastrointestinal é revestida por uma camada de muco, cujas principais funções são a proteção e lubrificação, mas atua também como barreira de difusão entre o lúmen e o epitélio (Peppas, Sallin, 1996; Edwards, 1997). Esta camada de muco desempenha ainda funções em nível do sistema imunitário, atuando como "scavenger" de radicais livres e mantendo elevadas concentrações de IgA e lisozima à superfície epitelial (Atuma et al., 2001; Edsman, Hägerström, 2005).

Os principais constituintes do muco são glicoproteínas (mucina), lípidios, eletrólitos e água, sendo que 
esta última contribui em $95 \%$ para o peso total. Diferenças na quantidade de muco secretada, na proporção dos constituintes e na composição das glicoproteínas têm sido encontradas em diferentes regiões do trato gastrointestinal (Atuma et al., 2001; Accilli et al., 2004; Smart, 2005).

A mucina é responsável pelas propriedades viscoelásticas do muco devido ao seu elevado peso molecular (1-40 MDa), ligações peptidicas, pontes dissulfídricas intramoleculares e interações hidrofóbicas (Edwards, 1997; Edsman, Hägerström, 2005). A ionização de resíduos sulfatados e ácido sálico a $\mathrm{pH}>2.6$ contribui para a carga negativa da mucina. Além disso, a abundância de grupos carboxílicos propicia o desenvolvimento de ligações de hidrogênio e interações eletrostáticas (Peppas, Sallin, 1996; Edsman, Hägerström, 2005).

A espessura da camada de muco resulta do balanço entre a secreção pelas células de Goblet e a sua degradação através de digestão enzimática ou erosão (Lehr, 1996; Atuma et al., 2001). Alguns estudos têm revelado a existência de duas camadas distintas de muco, que variam de espessura ao longo do trato gastrointestinal: uma camada aderente à mucosa e uma camada luminal que é facilmente removível por digestão enzimática, erosão ou por sucção (Matsuo et al., 1997; Atuma et al., 2001). Os valores de espessura reportados para as 2 camadas variam bastante consoante o modelo e a técnica utilizada. Atuma et al. (2001) mediram in vivo a espessura destas duas camadas desde o estômago ao cólon de ratos através de microscopia intravital e verificaram que o colón apresentava a maior espessura de muco $(830 \pm 110 \mu \mathrm{m})$, sendo contudo a camada aderente à mucosa mais espessa no estômago $(154 \pm 16 \mu \mathrm{m})$. Ensaios in vitro em que se compararam a espessura de muco no estômago, jejuno, cego e cólon proximal de ratos, revelaram o cego como tendo menor espessura de muco e o estômago no extremo oposto, sendo os valores inferiores aos resultados dos testes in vivo (Rubinstein, Tirosh, 1994). Matsuo et al. (1997), através de técnica in vitro mediram a espessura de muco em diferentes regiões do cólon humano referindo valores bastante mais baixos que aqueles determinados por microscopia intravital (Atuma et al., 2001), particularmente no cego e cólon proximal, o que reflete as diferenças entre o modelo e a técnica usada. O esôfago, ao contrário do resto do trato gastrointestinal não é revestido por muco, sendo a função lubrificante desempenhada pela saliva (Batchelor, 2005).

A taxa de renovação do muco no trato gastrointestinal tem sido pouco investigada e os dados obtidos em modelos animais (ratos) referem que é mais rápida no estômago e intestino delgado que no cólon. Além disso, a sensibilidade à estimulação da secreção de muco é mais baixa no cólon (Lehr et al., 1991; Rubinstein, Tirosh, 1994).

\section{MUCOADESÃO NO TRATO GASTROINTESTINAL}

\section{Definição}

O conceito de bioadesão foi introduzido na literatura farmacêutica no início da década de 1980, e desde então tem sido alvo de imensa investigação no âmbito da compreensão dos mecanismos adjacentes e no desenvolvimento de formas farmacêuticas de administação oral, bucal, ocular, nasal e vaginal.

A bioadesão tem sido referida como a adesão entre um material sintético ou natural e a superfície de um tecido, nomeadamente o epitélio da mucosa. O termo mucoadesão é utilizado quando a adesão ocorre entre o material e a camada de muco que reveste a mucosa (Park, Robinson, 1984; Lee et al., 2000; Edsman, Hägerström, 2005; Smart, 2005). Como o trato gastrointestinal é maioritariamente revestido por muco, o termo mucoadesão irá ser empregue nesta revisão.

\section{Potenciais vantagens do desenvolvimento de sistemas mucoadesivos}

As grandes vantagens da utilização deste conceito no desenvolvimento de formas farmacêuticas de administração oral residem na capacidade de prolongar o tempo de residência no local de absorção do fármaco, permitindo a sua completa dissolução e posterior absorção. Além disso, permite criar um contacto mais próximo entre a forma farmacêutica e a membrana absorvente, reduzindo a barreira de difusão e protegendo o fármaco da degradação no lúmen do trato gastrointestinal (Park, Robinson, 1984; Harris et al., 1990; Haeberlin, Friend, 1992; Lehr, 1996; Grabovac et al., 2005). A vantagem final seria permitir um regime de administração única diária, aumentando a adesão à terapêutica e reduzindo os efeitos adversos (Lee et al., 2000).

\section{Teorias propostas para a mucoadesão}

Para fundamentar o fenômeno da mucoadesão, várias teorias têm sido apresentadas. De entre as teorias desenvolvidas até ao momento, as mais referidas são a teoria eletrônica, a de adsorção, a do umedecimento, a de difusão e a de fratura (Tabela I). Contudo, o processo mucoadesivo não pode ser explicado no seu todo por uma das teorias, mas uma combinação de várias poderá ajudar a fundamentar este processo que varia consoante a formulação e as características fisiológicas, como a espessura da camada de muco (Edsman, Hägerström, 2005).

Normalmente, este processo ocorre em duas fases: 
a fase de contato e a fase de consolidação. Na primeira fase é necessário que ocorra um contato próximo entre o polímero mucoadesivo e a camada de muco. Como consequência, ocorre a transferência de água da camada de muco para o polímero, resultando no intumescimento (swelling) deste último. Deste modo, as cadeias do polímero adquirem maior mobilidade para poderem interpenetrar com as cadeias glicoproteicas do muco. O estabelecimento subsequente de ligações químicas entre o polímero e o muco contribui para a consolidação do fenômeno mucoadesivo (Smart, 2005; Ugwoke et al., 2005).

\section{FATORES COM INFLUÊNCIA NA MUCOADESÃO}

Têm sido descritos diversos fatores que afetam a mucoadesão e que se relacionam com as propriedades dos polímeros e com as características fisiológicas do trato gastrointestinal, encontrando-se sistematizados em algumas revisões (Ahuja et al., 1997; Lee et al., 2000; Vasir et al., 2003).

\section{Fatores relacionados com o polímero}

A influência do peso molecular e do grau de crosslinking depende do tipo de polímero mucoadesivo. O peso molecular ótimo é diferente para diferentes polímeros e depende da flexibilidade e da conformação das cadeias do polímero (Lee et al., 2000; Smart, 2005). Verificou-se que no caso do ácido polícrílico, a adesão foi superior para o peso molecular de 1000000 , enquanto que a adesão aumentava com o aumento do peso molecular no caso da carboximetilcelulose (Tobyn et al., 1996). A coesão do polímero pode ser mantida mediante um grau de crosslinking elevado. Contudo, a difusão de água do muco para o polímero ocorre em menor extensão e a velocidade mais baixa, o que pode condicionar o intumescimento do polímero e a flexibilidade das cadeias, limitando a interdifusão destas com as cadeias glicoproteicas da camada de muco e a exposição de locais ativos para o posterior estabelecimento de ligações (Vasir et al., 2003; Edsman, Hägerström, 2005; Smart, 2005). O efeito da concentração é distinto para as formulações sólidas e para as líquidas ou hidratadas. No primeiro caso, o aumento da concentração

TABELA I - Teorias propostas para fundamentar o processo mucoadesivo

\begin{tabular}{ll}
\hline Teoria & Mecanismo Proposto \\
\hline Electrônica & $\begin{array}{l}\text { Formação de uma bicamada elétrica na interface, devido } \\
\text { às diferentes cargas eléctricas do polímero e do muco, } \\
\text { ocorrendo transferência de elétrons entre as } 2 \text { camadas }\end{array}$ \\
Adsorção & $\begin{array}{l}\text { Salienta o papel das forças de Van der Waals, pontes de } \\
\text { hidrogênio e interações hidrofóbicas }\end{array}$
\end{tabular}

Umedecimento

Considera a importância da energia superficial do polímero e do muco e a energia interfacial
Difusão
Interdifusão das cadeias do polímero e do muco através da interface. Depende dos coeficientes de difusão; da concentração, comprimento das cadeias e sua mobilidade do polímero; tempo e pressão de contacto

Fratura
Assume que a fratura ocorre na interface entre o polímero e a camada de muco e que a força de fratura é igual à força de mucoadesão.
(Peppas, Sallin, 1996)

(Smart, 2005)

(Lee et al., 2000)

(Woodley, 2001)

(Smart, 2005)

(Ahuja et al., 1997)

(Edsman, Hägerström, 2005)

(Lehr et al., 1992)

(Ahuja et al., 1997)

(Smart, 2005)

(Peppas, Sallin, 1996)

(Lee et al., 2000)

(Smart, 2005)

(Edsman, Hägerström, 2005)

(Smart, 2005)

(Edsman, Hägerström, 2005) 
conduz a um aumento da força de mucoadesão. Para as formulações líquidas ou hidratadas existe um valor ótimo de concentração acima do qual as moléculas mudam de conformação, reduzindo a flexibilidade das cadeias (Lee et al., 2000; Ugwoke et al., 2005).

A estrutura química do polímero influencia algumas propriedades importantes na mucoadesão. A hidrofilia do polímero é importante para a sua hidratação através da transferência de água do muco e consequente intumescimento e exposição de grupos que possam estabelecer interação com as cadeias glicoprotéicas. A presença de grupos hidroxila, carboxila ou amina podem contribuir para o estabelecimento de ligações de hidrogênio ou pontes dissulfureto no caso de presença de grupos sulfidrilo (Mortazavi, 1995; Bernkop Schnurch et al., 1999). Polímeros com grupos ionizáveis podem interagir de forma eletrostática com o muco carregado negativamente, dependendo do pH do meio (Smart et al., 1984; Henriksen et al., 1996; Edsman, Hägerström, 2005).

\section{Fatores relacionados com as condições fisiológicas}

$\mathrm{O}$ valor do $\mathrm{pH}$ no trato gastrointestinal influencia a carga à superfície do muco e do polímero (se este possuir grupos ionizáveis), logo pode afetar a interação entre o polímero e o muco. O pH pode afetar ainda o grau de hidratação de alguns polímeros como o ácido poliacrílico (Ahuja et al., 1997; Lee et al., 2000; Ugwoke et al., 2005). A hidratação e intumescimento do polímero dependem da sua concentração, da força iônica e da presença de água. A mucoadesão é máxima para um volume de água ideal. Uma incompleta hidratação resulta numa baixa exposição dos grupos responsáveis pelas interações. Por outro lado, uma sobrehidratação resulta na perda de coesão do polímero, diminuindo a mucoadesão. Logo, a velocidade e extensão de hidratação devem ser controladas por processos como o cross-linking ou introdução de grupos hidrofóbicos (Mortazavi, Smart, 1993; Smart, 2005).

A extensão da interação entre o polímero e o muco depende também da viscosidade, espessura e taxa de renovação do muco. O tempo de residência de um polímero mucoadesivo no trato gastrointestinal poderá ser limitado pela taxa de renovação do muco, uma vez que a interação polímero-muco pode ser mais forte que a interação entre as 2 camadas de muco. Logo, um sistema mucoadesivo teria mais sucesso na zona do trato gastrointestinal onde a taxa de renovação do muco é mais lenta (Rubinstein, Tirosh, 1994; Lee et al., 2000). Além disso, as diferenças nos açúcares e suas quantidades na camada de muco, fazem variar o comportamento dos mucoadesivos ao longo do trato gastrointestinal (Accilli et al., 2004).
O tempo inicial de contato também é crítico na extensão de hidratação do polímero e na interpenetração das cadeias do polímero nas cadeias glicoprotéicas do muco (Tobyn et al., 1995; Vasir et al., 2003; Krauland et al., 2006)

\section{BIOADESÃO NO ESÔFAGO}

A mucosa do esôfago, ao contrário do restante trato gastrointestinal, não é revestida por muco, logo a adesão à mucosa será referida como bioadesão. A baixa permeabilidade do esôfago condiciona a absorção sistêmica de fármacos. Contudo, o uso de fármacos com ação tópica pode ser benéfica no tratamento de algumas patologias locais como infecções fúngicas, câncer do esôfago, disfunção da motilidade ou danos provocados pelo refluxo gastroesofágico (Batchelor, 2005).

O tempo de trânsito de formas farmacêuticas através do esôfago é relativamente rápido, o que tem motivado a investigação em sistemas bioadesivos que prolonguem o contato com a mucosa, aumentando a eficácia dos fármacos de ação local. Vários autores têm sugerido a adesão de formas farmacêuticas sólidas, como comprimidos e cápsulas, ao epitélio esofágico, mesmo que a formulação não tenha esse objectivo, provocando lesões no epitélio (McCord, Clouse, 1990; Batchelor, 2005).

A bioadesão ao esôfago de formulações líquidas tem sido investigada com o objetivo de proteção da mucosa e de libertação de fármacos. Foi evidenciado aumento significativo de retenção no esôfago (até 60 minutos) de soluções de alginato, através de ensaios in vitro em mucosa de porco (Batchelor et al., 2002). Estas soluções foram incorporadas com fármaco e avaliada a bioadesão pelo mesmo método e verificou-se aumento do tempo de residência no esôfago relativamente a soluções aquosas (Batchelor et al., 2004). Dobrozsi et al. (1999) estudaram a bioadesão do sucralfato e compararam com hidrogel de Carbopol 934P em ratos, in vitro, pela técnica de reviragem do esôfago, obtendo resultados semelhantes aos obtidos em humanos no que se refere à bioadesão do sucralfato (Dobrozsi et al., 1999). Esta técnica foi também utilizada para evidenciar a bioadesão de suspensões de alginato em esôfago de porco, utilizando diferentes veículos miscíveis com água, (Richardson et al., 2004). Säkkinen et al. (2004) mostraram através de $\gamma$-cintigrafia que cápsulas com grânulos de quitosana demoraram 1,75 horas a chegar ao estômago devido não só à adesão da cápsula, mas também à adesão dos grânulos de quitosano (Säkkinen et al., 2004). Contudo, McCargar et al. (2001) propuseram que os ensaios in vitro, usando mucosa esofágica de porco não eram preditivos do trânsito através do esôfago nos humanos, apontando a 
$\gamma$-cintigrafia como o método de escolha (McCargar et al., 2001). Os ensaios in vitro usando mucosa esofágica permitem avaliação rápida do perfil bioadesivo de várias formulações, mas não equacionam a presença de alimentos, motilidade e enzimas digestivas. Além disso, a falta de reprodutibilidade nas condições experimentais e técnicas usadas condicionam a extrapolação dos resultados para os humanos (Batchelor, 2005).

\section{MUCOADESÃO NO ESTÔMAGO}

Em algumas circunstâncias, pode ser benéfico prolongar o tempo de retenção de formas farmacêuticas no estômago, de forma a otimizar o efeito terapêutico de fármacos, particularmente aqueles que são absorvidos na zona proximal do GI, os que são menos solúveis ou degradados em meio alcalino ou quando se pretende libertação prolongada no estômago ou no intestino delgado (Park, Robinson, 1984; Rouge et al., 1996; Talukder, Fassihi, 2004). Neste sentido, várias abordagens têm sido testadas, entre as quais a adesão de formas farmacêuticas à mucosa gástrica ou à camada de muco que a reveste (Park, Robinson, 1984).

Ch'ng et al. (1985) estudaram a mucoadesão do policarbophil e outros derivados do ácido poliacrílico in vitro em mucosa gástrica de rato e demonstraram que cápsulas contendo o material mucoadesivo exibiam maior tempo de trânsito gastrointestinal (Ch'ng et al., 1985). O policarbophil foi estudado em esferas contendo albumina e clorotiazida, comparando-se o perfil de mucoadesão com esferas controle. A avaliação do tempo de retenção in vivo, em ratos, demonstrou que $90 \%$ das esferas formuladas com policarbophil permaneceram no estômago após 6 horas, aumentando a biodisponibilidade do fármaco, Figura 1 (Longer et al., 1985).

Outro ensaio in vivo, em ratos, demonstrou que partículas de resina de troca iônica revestidas com Carbopol 934P sofriam esvaziamento gástrico mais lento que o controle ou partículas revestidas com carboximetilcelulose de sódio (Smart, Kellaway, 1989). Preda e Leucota (2003) prepararam microsferas de ácido políacrílico e verificaram, através de ensaios in vitro e in vivo em ratos, que possuíam boas propriedades mucoadesivas, expressas no maior tempo de retenção gástrico e intestinal (Preda, Leucuta, 2003). Foi demonstrada boa capacidade mucoadesiva para partículas de colestiramina, logo atrás do Carbopol, e com melhor resultado que outros conhecidos mucoadesivos. A mucoadesão foi avaliada em mucosa de porco e mucosa humana e verificou-se que esta era mais forte no primeiro caso (Jackson, Perkins, 2001).

Säkkinen et al. (2003) observaram, através de estu-



FIGURA 1 - Perfil de absorção de clorotiazida em ratos a partir de: fármaco em pó $(\bigcirc)$, esferas de albumina $(\mathbf{O})$ e esferas de albumina e policarbofil $(\diamond)$. Reproduzido de Longer et al., 1985.

dos de biodisponibilidade em indivíduos saudáveis, um atraso na absorção de ibuprofeno e furosemida veiculados em microgrânulos de quitosana na forma microcristalina, à qual atribuíram à adesão dos grânulos à mucosa gástrica e correspondente aumento do tempo de retenção (Säkkinen et al., 2003). Tobyn et al. (1996) estudaram a mucoadesão, em mucosa gástrica de porco (in vitro), de derivados do ácido políacrílico, de carboximetilcelulose de vários graus de viscosidade e de alguns polissacáridos de forma a estudar as variáveis relacionadas com o polímero que influenciam a mucosão gástrica (Tobyn et al., 1996).

Harris et al. (1990) compararam o trânsito gastrointestinal de cápsulas preenchidas com esferas formuladas com Policarbophil ou Carbopol 934P, através de $\gamma$-cintigrafia em indivíduos saudáveis. Verificaram que nem o Carbopol 934P nem o Policarbophil afetaram significativamente o trânsito das formulações estudadas, em relação ao controle (lactose), contrariando os resultados obtidos em ensaios in vitro e in vivo em ratos e porcos (Harris et al., 1990). Khosla e Davis (1987) também demonstraram, através de $\gamma$-cintigrafia, que pellets de Policarbophil não exibiam um esvaziamento gástrico mais lento, ao contrário do que se tinha verificado em ensaios com ratos e cães (Khosla, Davis, 1987).

As diferenças de resultados observados nos testes in vitro usando mucosa gástrica relacionam-se com diferenças na região do estômago em estudo, tempo e força de contato entre o polímero e a muco, velocidade de separação, grau de pré-hidratação do polímero, composição do meio de teste (pH, eletrólitos). Logo, é de crucial importân- 
cia desenvolver um método e validar todas as variáveis de forma a aumentar a reprodutibilidade dos resultados obtidos por vários grupos (Tobyn et al., 1995). Além disso, o insucesso da mucoadesão gástrica em estudos humanos realça a falta de correlação com os resultados obtidos em modelos animais, devido a muitos destes ensaios não considerarem a especificidade do sistema gastrointestinal humano. A rápida taxa de renovação do muco no estômago, a elevada acidez e a motilidade gástrica podem ser as causas deste insucesso (Rubinstein, Tirosh, 1994; Davis, 2005).

\section{MUCOADESÃO NO INTESTINO DELGADO}

O intestino delgado é o local preferencial de absorção de muitos fármacos. Contudo, o tempo de trânsito através do intestino delgado é curto (3-4 horas) o que condiciona a performance de sistemas de liberação prolongada de fármacos absorvidos nesta zona. Logo, a mucoadesão de formas farmacêuticas no intestino delgado tem sido alvo de investigação (Wilding, 2000; Davis, 2005). Vários métodos têm sido desenvolvidos para o estudo da mucoadesão de formas farmacêuticas na mucosa gastrointestinal. No entanto, são poucos os métodos que retratam com alguma fidelidade a camada de muco que reveste o trato gastrointestinal e à qual a adesão é testada. Estes são normalmente baseados em sistemas de fluxo (Figura 2), utilizando como modelo mucosa intestinal de rato ou porco, perfusão em segmentos de intestino ou perfusão 'in situ' (Lehr et al., 1990; Keely et al., 2005).



FIGURA 2 - Esquema representativo de um método de fluxo para estudo da mucoadesão de micropartículas em mucosa animal. Reproduzido de De Ascentiis et al, 1995.

Uma das técnicas mais usadas é a tensiometria que mede a força necessária para destacar um dado polímero de uma superfície ou mucosa (Figura 3). Este método é muito usual na avaliação das propriedades mucoadesivas de vários polímeros, de forma a estabelecer comparação (Lehr et al., 1992; Grabovac et al., 2005). Contudo, as condições experimentais não mimetizam o que acontece no meio fisiológico (Keely et al., 2005). Este e outros métodos encontram-se extensamente revistos na literatura (Tamburic, Craig, 1997; Chary et al., 1999; Santos et al., 1999; Takeuchi et al., 2005).

Os resultados obtidos in vitro, muitas vezes animadores, necessitam ser confirmados por ensaios in vivo.



FIGURA 3 - Esquema representativo de um método de estudo da mucoadesão (microbalança CAHN) baseado na medição da força de tensão entre a mucosa e forma farmacêutica. Adaptado de Santos et al., 1999.

A farmacocinética tem sido usada como medida indireta de mucoadesão, por comparação da quantidade de fármaco absorvida e do tempo de absorção, de formulações adesivas e não adesivas (Hosny, 1996; Akiyama et $a l ., 1998)$. A $\gamma$-cintigrafia é um método não-invasivo e permite analisar o tempo de residência de formas farmacêuticas no trato gastrointestinal in vivo. Tem sido usada para avaliar o trânsito gastrointestinal de formas farmacêuticas mucoadesivas em indivíduos saudáveis, de forma a correlacionar com os dados obtidos nos ensaios in vitro e in vivo com modelos animais (Wilding, 1995; Wilding, 2000; Wilding et al., 2001). Nas Tabelas II e III são apresentados alguns estudos in vitro $e$ in vivo de mucoadesão no intestino delgado e respectivos métodos e modelos.

Apesar dos resultados bastante promissores obtidos nos métodos in vitro e in vivo, usando modelos animais, os sistemas mucoadesivos têm ficado aquém das expectativas em humanos. Os modelos animais envolvendo ratos, por- 
TABELA II - Compilação de alguns ensaios sobre mucoadesão intestinal de formas farmacêuticas, usando ensaios in vitro

\begin{tabular}{|c|c|c|c|}
\hline Método & Polímero & Modelo & Referência \\
\hline Sistema de fluxo & $\begin{array}{l}\text { Copolímeros do } \\
\text { ácido metacrílico }\end{array}$ & $\begin{array}{c}\text { Mucosa } \\
\text { intestinal de rato }\end{array}$ & (Achar, Peppas, 1994) \\
\hline & $\begin{array}{l}\text { Poli(2-hidroxi-etil) } \\
\text { metacrilato }+ \text { PEG }\end{array}$ & & (De Ascentiis et al., 1995) \\
\hline $\begin{array}{l}\text { Perfusão e quant. } \\
\text { por fluorimetria }\end{array}$ & Quitosano & $\begin{array}{c}\text { Mucosa } \\
\text { intestinal de rato }\end{array}$ & (Shimoda et al., 2001) \\
\hline & $\begin{array}{l}\text { Carbopol 934P e } \\
\text { o seu sal sódico }\end{array}$ & & (Nakanishi et al., 1998) \\
\hline $\begin{array}{l}\text { Perfusão e avaliação } \\
\text { por microscopia de } \\
\text { fluorescência }\end{array}$ & Alginato & $\begin{array}{c}\text { Mucosa } \\
\text { intestinal de rato }\end{array}$ & (Coppi et al., 2006) \\
\hline \multirow[t]{3}{*}{ Tensiometria } & $\begin{array}{c}\text { Quitosano } \\
\text { Policarbophil } \\
\text { HPC } \\
\text { Goma }\end{array}$ & $\begin{array}{c}\text { Mucosa } \\
\text { intestinal de porco }\end{array}$ & (Lehr et al., 1992) \\
\hline & $\begin{array}{c}\text { Carbopol 934P e 974P } \\
\text { Policarbofil } \\
\text { Hipromelose }\end{array}$ & Disco de plexiglass & $\begin{array}{l}\text { (Prudat-Christiaens } \\
\text { et al., 1996) }\end{array}$ \\
\hline & $\begin{array}{c}\text { Tiómeros } \\
\text { (policarbofil e CMC) }\end{array}$ & Mucosa intestinal de porco & $\begin{array}{l}\text { (Bernkop-Schnurch, } \\
\text { Steininger, 2000) }\end{array}$ \\
\hline Variação de peso & Alginato & Mucosa intestinal de rato & (Rastogi et al., 2007) \\
\hline $\begin{array}{l}\text { Quantificação por } \\
\text { fluorimetria }\end{array}$ & $\begin{array}{c}\text { Polimetacrilato } \\
\text { N-trimetil-quitosano }\end{array}$ & $\begin{array}{l}\text { Cultura cellular intestinal } \\
\text { humana muco-secretora }\end{array}$ & (Keely et al., 2005) \\
\hline
\end{tabular}

TABELA III - Compilação de alguns ensaios sobre mucoadesão intestinal de formas farmacêuticas, usando ensaios in vivo

\begin{tabular}{lccc}
\hline Método & Polímero & Modelo & Referência \\
\hline Perfusão in situ & Carbopol 934PPolicarbofil & Rato & (Lehr et al., 1990) \\
\hline $\begin{array}{l}\text { Administração } \\
\text { Intraduodenal e } \\
\text { quant. por fluorimetria }\end{array}$ & Ácido polimetarílico + PEG & Rato & (Goto et al., 2006) \\
\hline Estudo Farmacocinético & Quitosano & Rato & (Shimoda et al., 2001) \\
\hline & Policarbofil & Cães (Beagle) & (Hosny, 1996) \\
\hline$\gamma$-cintigrafia & Der. ácido poliacrílico & Homem & (Akiyama et al., 1998) \\
\hline
\end{tabular}

cos e cães não são bons modelos para o trato gastrointestinal, especialmente no que diz respeito ao trânsito gastrointestinal (Davis, 2005). Foi demonstrado através de $\gamma$-cintigrafia, em humanos, que o trânsito através do intestino delgado não era significativamente afetado por formulações contendo Policarbofil ou Carbopol 934P (Harris et al., 1990). Muitos dos métodos de estudo da mucoadesão não têm em conta a heterogeneidade da ana- 
tomia e fisiologia do trato gastrointestinal, como as diferenças de motilidade, actividade enzimática, $\mathrm{pH}$ e taxa de renovação de muco. Além disso, a velocidade de renovação de muco no intestino delgado é rápida e a motilidade é intensa, o que condiciona o desempenho das formas farmacêuticas mucoadesivas nesta zona do trato gastrointestinal (Wilding, 2000; Davis, 2005; Keely et al., 2005).

\section{MUCOADESÃO NO CÓLON}

Durante os últimos anos, vários sistemas de libertação de fármacos no cólon têm sido desenvolvidos com o intuito de atuação local (doença inflamatória intestinal) ou para absorção sistêmica de fármacos que são degradados pela acidez do estômago ou atividade enzimática do intestino delgado (Watts, Illum, 1997; Yang et al., 2002; Basit, 2005; Schiller et al., 2005). A eficácia destes sistemas depende do seu tempo de residência no cólon, o qual apresenta enorme variabilidade inter e intra-individual (Abrahamsson et al., 1996; Wilding et al., 2001). Logo, a reprodutibilidade terapêutica de formas farmacêuticas destinadas ao cólon pode ser bastante afetada.

Uma das estratégias para aumentar o tempo de residência destes sistemas no cólon e a sua reprodutibilidade é a mucoadesão. Apesar dos resultados pouco satisfatórios dos sistemas mucoadesivos no estômago e intestino delgado em humanos, a mucoadesão no cólon poderá ser mais bem sucedida devido às diferenças anatomo-fisiológicas desta zona do trato gastrointestinal. O cólon apresenta taxa de renovação do muco e sensibilidade a estímulos mucosecretores mais baixas que o estômago e o intestino delgado. Portanto, o tempo de residência de um sistema mucoadesivo no cólon é menos limitado pela renovação do muco. Além disso, a motilidade no cólon é mais baixa, o que contribui para maior tempo de residência das formas farmacêuticas, facilitando assim o estabelecimento de interação com as glicoproteínas do muco (Lehr et al., 1991; Rubinstein, Tirosh, 1994). Contudo, na literatura são escassos os estudos que abordam a mucoadesão no cólon, quer em estudos in vitro quer in vivo. A seguir são apresentados alguns dos estudos elaborados nesta área.

Rihová et al. (1992) estudaram a mucoadesão de copolímeros de $\mathrm{N}$-(2-hidroxipropil) matacrilamida com cadeias laterais de sacáridos (galactosamina, fucosilamina, glucosamina, manosamina) em segmentos de cólon de porcos-da-índia. Estas cadeias reconhecem especificamente resíduos glicoproteicos no muco ou no epitélio. Os resultados sugeriram que o conteúdo em fucosilamina é um dos determinantes para a especificidade da mucoadesão (Ríhová et al., 1992). Kakoulides et al. (1998) mediram a mucoadesão de azoderivados ácido poliacrílico em mucosa colônica de ratos. Verificaram que a capacidade mucoadesiva era dependente do nível de cross-linking do polímero (Kakoulides et al., 1998). Wittaya-Areekul et al. (2006) testaram a mucoadesão in vitro, em mucosa colônica de porco, de micropartículas de alginato revestidas com quitosano, usando o método do aparelho de dissolução (Wittaya-Areekul et al., 2006). Haupt et al. (2006) estudaram a capacidade mucoadesiva de filmes de quitosana e goma guar em mucosa colônica de ratos, através de tensiometria. Com este estudo concluíram que as propriedades mucoadesivas dos filmes aumentavam com a proporção de quitosana no filme (Haupt et al., 2006).

\section{CONCLUSÃO}

A mucoadesão de formas farmacêuticas no trato gastrointestinal humano, particularmente no estômago e intestino delgado, tem ficado aquém das expectativas geradas pelos bons resultados dos estudos em modelos animais. Contudo, o cólon apresenta algumas características fisiológicas que são vantajosas para o sucesso de formas farmacêuticas mucoadesivas. Apesar dos resultados promissores destes estudos, mantém-se o problema da falta de um método universal que possa ser usado para testar vários polímeros, em condições padronizadas e que tenham em conta as condicionantes anatomo-fisiológicas do trato gastrointestinal humano. Além disso, são necessários estudos em humanos para testar a correlação com os resultados obtidos em ensaios in vitro e in vivo em modelos animais. Conjuntamente com os estudos de mucoadesão são necessários estudos de farmacocinética para determinar a velocidade e extensão de absorção dos fármacos após a sua liberação do sistema mucoadesivo.

\section{ABSTRACT \\ Mucoadhesion studies in the gastrointestinal tract to increase oral drug bioavailability}

The oral bioavailability of many drugs can be limited by the residence time of pharmaceutical dosage forms in the gastrointestinal tract. Mucoadhesion has been proposed as a method to increase residence time at a specific area, hence increasing the therapeutic effect of drugs. Most research efforts on mucoadhesion have focused on the stomach and small intestine, with promising results observed from in in vitro studies. However, $\gamma$-scintigraphy data obtained in human studies have revealed the lack of success of mucoadhesion approaches in order to increase the contact time of formulations in the upper gut. The lack of in vitro/in 
vivo correlation can be attributed to the complex nature of the human gastrointestinal tract, with most in vitro models providing little resemblance to the in vivo situation, such as motility, $\mathrm{pH}$, mucus thickness and mucus turnover, presence of enzymes and food. In the colon, the mucus turnover, the sensibility to mucus secretory stimulus and motility are lower than in the stomach and small intestine. Therefore, colonic mucoadhesion may be a more successful approach. Nevertheless, more studies in animals and humans are needed to evaluate its potential, as well as, pharmacokinetic studies to investigate drug release and absorption from mucoadhesive systems.

UNITERMS: Drugs/oral bioavailability. Mucoadhesion/ in vitro and in vivo studies. Gastrointestinal tract/ mucoadhesion study. Drugs/absortion.

\section{REFERÊNCIAS BIBLIOGRÁFICAS}

ABRAHAMSSON, B.; ALPSTEN, M.; JONSSON, U.E.; LUNDBERG, P.J.; SANDBERG, A.; SUNDGREN, M.; SVENHEDEN, A.; TOLLI, J. Gastro-intestinal transit of a multiple-unit formulation (metoprolol CR/ZOK) and a non-disintegrating tablet with the emphasis on colon. Int. J. Pharm., v.140, n.2, p.229-235, 1996.

ACCILLI, D.; MENGHI, G.; BONACUCINA, G.; DI MARTINO, P.; PALMIERI, G.F. Mucoadhesion dependence of pharmaceutical polymers on mucosa characteristics. Eur. J. Pharm. Sci., v.22, n.225-234, 2004.

ACHAR, L.; PEPPAS, N.A. Preparation, characterization and mucoadhesive interactions of poly(methacrylic acid) copolymers with rat mucosa. J. Control. Release, v.31, p.271-276, 1994.

ADKIN, D.A.; DAVIS, S.S.; SPARROW, R.A.; WILDING, I.R. Colonic transit of different sized tablets in healthy subjects. J. Control. Release, v.23, p.147-156, 1993.

AHUJA, A.; KHAR, R.K.; ALI, J. Mucoadhesive drug delivery systems. Drug Dev. Ind. Pharm., v.23, n.5, p.489-515, 1997.
AKIYAMA, Y.; NAGAHARA, N.; NARA, E.; KITANO, M.; SUSUMU, I.; YAMAMOTO, I.; AZUMA, J.; OGAWA, Y. Evaluation of oral mucoadhesive microspheres in man on the basis of the pharmacokinetics of furosemide and riboflavin, compounds with limited gastrointestinal absorption sites. J. Pharm. Pharmacol., v.50, p.159-166, 1998.

ATUMA, C.; STRUGALA, V.; ALLEN, A.; HOLM, L. The adherent gastrointestinal mucus gel layer: thickness and physical state in vivo. Am. J. Physiol. Gastrointest. Liver Physiol., v.280, p.922-929, 2001.

BASIT, A.W. Advances in colonic drug delivery. Drugs, v.65, n.14, p.1991-2007, 2005.

BATCHELOR, H. Bioadhesive dosage forms for esophageal drug delivery. Pharm. Res., v.22, n.2, p.175-181, 2005.

BATCHELOR, H.K.; BANNING, D.; DETTMAR, P.W.; HAMPSON, F.C.; JOLLIFFE, I.G.; CRAIG, D.Q.M. An in vitro mucosal model for prediction of the bioadhesion of alginate solutions to the oesophagus. Int. J. Pharm., v.238, p.123-132, 2002.

BATCHELOR, H.K.; TANG, M.; DETTMAR, P.W.; HAMPSON, F.C.; JOLLIFFEB, I.G.; CRAIG, D.Q.M. Feasibility of a bioadhesive drug delivery system targeted to oesophageal tissue. Eur. J. Pharm. Biopharm., v.57, p.295-298, 2004.

BERNKOP-SCHNURCH, A.; STEININGER, S. Synthesis and characterisation of mucoadhesive thiolated polymers. Int. J. Pharm., v.194, p.239-247, 2000.

BERNKOP SCHNURCH, A.; SCHWARZ, V.; STEININGER, S. Polymers with thiol groups: a new generation of mucoadhesive polymers? Pharm. Res., v.16, n.6, p.876-881, 1999.

CH'NG, H.S.; PARK, H.; KELLY, P.; ROBINSON, J.R. Bioadhesive polymers as platforms for oral controlled drug delivery II: Synthesis and evaluation of some swelling, water-insoluble bioadhesive polymers. J. Pharm. Sci., v.74, n.4, p.399-405, 1985.

CHARY, R.B.R.; VANI, G.; RAO, Y.M. In vitro and in vivo adhesion testing of mucoadhesive drug delivery systems. Drug Dev. Ind. Pharm., v.25, n.5, p.685-690, 1999. 
COPPI, G.; SALA, N.; BONDI, M.; SERGI, S.; IANNUCCELLI, V. Ex-vivo evaluation of alginate microparticles for Polymyxin B oral administration. $J$. Drug Target., v.14, n.9, p.599-606, 2006.

COUPE, A.J.; DAVIS, S.S.; WILDING, I.R. Variation in gastrointestinal transit of pharmaceutical dosage forms in healthy subjects. Pharm. Res., v.8, n.3, p.360-364, 1991.

DAVIS, S.S. Formulation strategies for absorption windows Drug Discov. Today, v.10, n.4, p.249-257, 2005.

DE ASCENTIIS, A.; DEGRAZIA, J.L.; BOWMAN, C.N.; COLOMBO, P.; PEPPAS, N.A. Mucoadhesion of poly(2-hydroxyethyl methacrylate) is improved when linear poly(ethylene oxide) chains are added to the polymer network. J. Control. Release, v.33, n.1, p.197-201, 1995.

DEVEREUX, J.E.; NEWTON, J.M.; SHORT, M.B. The influence of density on the gastrointestinal transit of pellets. J. Pharm. Pharmacol., v.42, p.500-1, 1990.

DOBROZSI, D.J.; SMITH, R.L.; SAKR, A.A. Comparative mucoretention of sucralfate suspensions in an everted rat esophagus model. Int. J. Pharm., v.189, p.81-89, 1999.

EDSMAN, K.; HÄGERSTRÖM, H. Pharmaceutical applications of mucoadhesion for the non-oral routes. $J$. Pharm. Pharmacol., v.57, p.3-22, 2005.

EDWARDS, C. Physiology of the colorectal barrier. $A d v$. Drug Deliv. Rev., v.28, n.2, p.173-190, 1997.

FOLLONIER, N.; DOELKER, E. Biopharmaceutical comparison of oral multiple-unit and single-unit sustainedrelease dosage forms. S.T.P. Pharma Sci., v.2, p.141-158, 1992.

GOTO, T.; MORISHITA, M.; KAVIMANDAN, N.J.; TAKAYAMA, K.; PEPPAS, N.A. Gastrointestinal transit and mucoadhesive characteristics of complexation hydrogels in rats. J. Pharm. Sci., v.95, n.2, p.462-469, 2006.

GRABOVAC, V.; GUGGI, D.; BERNKOP-SCHNURCH, A. Comparison of the mucoadhesive properties of various polymers. Adv. Drug Deliv. Rev., v.57, p.1713-1723, 2005.
HAEBERLIN, B.; FRIEND, D.R. Anatomy and Physiology of the gastrointestinal tract: Implications for colonic drug delivery. In: Friend, D.R. eds. Oral colon-specific drug delivery. Boca Raton: CCR Press, 1992. cap.1, p.2-43.

HARDY, J.G. Colonic transit and drug delivery. In: Hardy, J.G., Davis, S.S.,Wilson, C.G. eds. Drug delivery to the gastrointestinal tract. New York: Ellis Horwood, 1989. cap.6, p.75-81.

HARRIS, D.; FELL, J.T.; SHARMA, H.L.; TAYLOR, D.C. GI transit of potential bioadhesive formulations in man: A scintigraphic study. J. Control. Release, v.12, p.45-53, 1990.

HAUPT, S.; ZIONI, T.; GATI, I.; KLEINSTERN, J.; RUBINSTEIN, A. Luminal delivery and dosing considerations of local celecoxib administration to colorectal cancer. Eur. J. Pharm. Sci., v.28, n.3, p.204211, 2006.

HENRIKSEN, I.; GREEN, K.L.; SMART, J.D.; SMISTAD, G.; KARLSEN, J. Bioadhesion of hydrated chitosans: An in vitro and in vivo study. Int. J. Pharm., v.145, n.1-2, p.231-240, 1996.

HOSNY, E.A. Formulation and comparative evaluation of bioadhesive containing diclofenac sodium and commercial enteric coated tablets in-vitro and in dogs. Int. J. Pharm., v.133, n.1-2, p.149-153, 1996.

JACKSON, S.J.; PERKINS, A.C. In vitro assessment of the mucoadhesion of cholestyramine to porcine and human gastric mucosa. Eur. J. Pharm. Biopharm., v.52, p.121127, 2001.

KAKOULIDES, E.P.; SMART, J.D.; TSIBOUKLIS, J. Azocrosslinked poly(acrylic acid) for colonic delivery and adhesion specificity: in vitro degradation and preliminary ex vivo bioadhesion studies. J. Control. Release, v.54, n.1, p.95-109, 1998.

KEELY, S.; RULLAY, A.; WILSON, C.; CARMICHAEL, A.; CARRINGTON, S.; CORFIELD, A.; HADDLETON, D.M.; BRAYDEN, D.J. In vitro and ex vivo intestinal tissue models to measure mucoadhesion of Poly(methacrylate) and N-Trimethylated chitosan polymers. Pharm. Res., v.22, n.1, p.38-49, 2005. 
KENDALL, R.A.; BASIT,A.W. The role of polymers in solid oral dosage forms. In: UCHEGBU, I.F.,SCHÄTZLEIN, A.G. Eds. Polymers in drug delivery. Boca Raton: Taylor and Francis, 2006. cap.6, p.35-48.

KHOSLA, R.; DAVIS, S.S. The effect of polycarbophil on the gastric emptying of pellets. J. Pharm. Pharmacol., v.39, p.47-49, 1987.

KRAULAND, A.H.; LEITNER, V.M.; GRABOVAC, V.; BERNKOP SCHNURCH, A. In vivo evaluation of a nasal insulin delivery system based on thiolated chitosan. J. Pharm. Sci., v.95, n.11, p.2463-2472, 2006.

LEE, J.W.; PARK, J.H.; ROBINSON, J.R. Bioadhesivebased dosage forms: The next generation. J. Pharm. Sci., v.89, p.850-866, 2000.

LEHR, C.-M. From sticky stuff to sweet receptors achievements, limits and novel approaches to bioadhesion. Eur. J. Drug Metab. Pharmacokinet., v.21, n.2, p.139148, 1996.

LEHR, C.-M.; BOUWSTRA, J.A.; SCHACHT, E.H.; JUNGINGER, H.E. in vitro evaluation of mucoadhesive properties of chitosan and some other natural polymers. Int. J. Pharm., v.78, p.43-48, 1992.

LEHR, C.-M.; BOUWSTRA, J.A.; TUKKER, J.J.; JUNGINGER, H.E. Intestinal transit of bioadhesive microspheres in an in situ loop in the rat - A comparative study with copolymers and blends based on poly(acrylic acid). J. Control. Release, v.13, p.51-62, 1990.

LEHR, C.-M.; POELMA, F.G.J.; JUNGINGER, H.E.; TUKKER, J.J. An estimate of turnover time of intestinal mucus gel layer in the rat in situ loop. Int. J. Pharm., v.70, p.235-240, 1991.

LONGER, M.A.; CH'NG, H.S.; ROBINSON, J.R. Bioadhesive polymers as platforms for oral controlled drug delivery III: oral delivery of chlorothiazide using a bioadhesive polymer. J. Pharm. Sci., v.74, n.4, p.406-411, 1985.

MATSUO, K.; OTA, H.;AKAMATSU, T.; SUGIYAMA, A.; KATSUYAMA, T. Histochemistry of the surface mucous gel layer of the human colon. Gut, v.40, n.6, p.782-789, 1997.
MCCARGAR, L.; CRAIL, D.; DANSEREAU, R.; MYERS, W.; LANE, M. The in-vitro porcine adhesion model is not predictive of the esophageal transit of risedronate tablets in humans. Int. J. Pharm., v.222, p.191-197, 2001.

MCCORD, G.S.; CLOUSE, R.E. Pill-induced esophageal strictures: clinical features and risk factors for development. Am. J. Med., v.88, p.512-518, 1990.

MORTAZAVI, S.A. An in vitro assessment of mucus/ mucoadhesive interactions. Int. J. Pharm., v.124, n.2, p.173-182, 1995.

MORTAZAVI, S.A.; SMART, J.D. An investigation into the role of water movement and mucus gel dehydation in mucoadhesion. J. Control. Release, v.25, p.197-203, 1993.

NAKANISHI, T.; KAIHO, F.; HAYASHI, M. Use of sodium salt of Carbopol 934P in oral peptide delivery. Int. J. Pharm., v.171, n.2, p.177-183, 1998.

PARK, K.; ROBINSON, J.R. Bioadhesive polymers as platforms for oral-controlled drug delivery: method to study bioadhesion. Int. J. Pharm., v.19, p.107-127, 1984.

PEPPAS, N.A.; SALLIN, J.J. Hydrogels as mucoadhesive and bioadhesive materials: A review. Biomaterials, v.17, p.1553-1561, 1996.

PREDA, M.; LEUCUTA, S.E. Oxprenolol-loaded bioadhesive microspheres: preparation and in vitro/ in vivo characterization. J. Microencapsul., v.20, n.6, p.777-789, 2003.

PRUDAT-CHRISTIAENS, C.; ARNAUD, P.; ALLAIN, P.; CHAUMEIL, J.C. Aminophylline bioadhesive tablets attempted by wet granulation. Int. J. Pharm., v.141, n.12, p.109-116, 1996.

RASTOGI, R.; SULTANA, Y.; AQIL, M.; ALI, A.; KUMAR, S.; CHUTTANI, K.; MISHRA, A.K. Alginate microspheres of isoniazid for oral sustained drug delivery. Int. J. Pharm., v.334, n.1-2, p.71-77, 2007.

RICHARDSON, J.C.; DETTMAR, P.W.; HAMPSON, F.C.; MELIA, C.D. Oesophageal bioadhesion of sodium alginate suspensions: particle swelling and mucosal retention. Eur. J. Pharm. Sci., v.23, p.49-56, 2004. 
RÍHOVÁ, B.; RATHI, R.C.; KOPECKOVÁ, P.; KOPECÉK, J. In vitro bioadhesion of carbohydrate containing $\mathrm{N}$-(2-hydroxypropyl)methacrylamide copolymers to the GI tract of guinea pigs. Int. J. Pharm., v.87, p.105-116, 1992.

ROUGE, N.; BURI, P.; DOELKER, E. Drug absorption sites in the gastrointestinal tract and dosage forms for sitespecific delivery. Int. J. Pharm., v.136, p.117-139, 1996.

RUBINSTEIN, A.; TIROSH, B. Mucus gel thickness and turnover in the gastrointestinal tract of the rat: response to cholinergic stimulus and implication for mucoadhesion. Pharm. Res., v.11, n.6, p.794-799, 1994.

SÄKKINEN, M.; LINNA, A.; OJALA, S.; JÜRJENSON, H.; VESKI, P.; MARVOLA, M. In vivo evaluation of matrix granules containing microcrystalline chitosan as a gel-forming excipient. Int. J. Pharm., v.250, p.227-237, 2003.

SÄKKINEN, M.; MARVOLA, J.; KANERVA, H.; LINDEVALL, K.; AHONEN, A.; MARVOLA, M. Scintigraphic verification of adherence of a chitosan formulation to the human oesophagus. Eur. J. Pharm. Biopharm., v.57, p.145-147, 2004.

SANTOS, C.A.; JACOB, J.S.; HERTZOG, B.A.; FREEDMAN, B.D.; PRESS, D.L.; HARNPICHARNCHAI, P.; MATHIOWITZ, E. Correlation of two bioadhesion assays: the everted sac technique and the CAHN microbalance. J. Control. Release, v.61, p.113-122, 1999.

SCHILLER, C.; FROHLICH, C.P.; GIESSMANN, T.; SIEGMUND, W.; MÖNNIKES, H.; HOSTEN, N.; WEITSCHIES, W. Intestinal fluid v.umes and transit of dosage forms as assessed by magnetic ressonance imaging. Aliment. Pharmacol. Ther., v.22, p.971-979, 2005

SHIMODA, J.; ONISHI, H.; MACHIDA, Y. Bioadhesive characteristics of chitosan microspheres to the mucosa of rat small intestine. Drug Dev. Ind. Pharm., v.27, n.6, p.567-576, 2001.

SMART, J.D. The basics and underlying mechanisms of mucoadhesion. Adv. Drug Deliv. Rev., v.57, p.1556-1568, 2005.
SMART, J.D.; KELLAWAY, I.W. Pharmaceutical factors influencing the rate of gastrointestinal transit in an animal model. Int. J. Pharm., v.53, p.79-83, 1989.

SMART, J.D.; KELLAWAY, I.W.; WORTHINGTON, H.E.C. An in-vitro investigation of mucosa-adhesive materials for use in controlled drug delivery. J. Pharm. Pharmacol., v.36, p.295-299, 1984.

TAKEUCHI, H.; THONGBORISUTE, J.; MATSUI, Y.; SUGIHARA, H.; YAMAMOTO, H.; KAWASHIMA, Y. Novel mucoadhesion tests for polymers and polymercoated particles to design optimal mucoadhesive drug delivery systems. Adv. Drug Deliv. Rev., v.57, p.15831594, 2005.

TALUKDER, R.; FASSIHI, R. Gastroretentive delivery systems: A mini review. Drug Dev. Ind. Pharm., v.30, n.10, p.1019-1028, 2004.

TAMBURIC, S.; CRAIG, D.Q.M. A comparison of different in vitro methods for measuring mucoadhesive performance. Eur. J. Pharm. Biopharm., v.44, p.159-167, 1997.

TOBYN, M.J.; JOHNSON, J.R.; DETTMAR, P.W. Factors affecting in vitro gastric mucoadhesion. I. Test Conditions and instrumental parameters. Eur. J. Pharm. Biopharm., v.41, n.4, p.235-241, 1995.

TOBYN, M.J.; JOHNSON, J.R.; DETTMAR, P.W. Factors affecting in vitro gastric mucoadhesion. II. Physical properties of polymers. Eur. J. Pharm. Biopharm., v.42, n.1, p.56-61, 1996.

TULEU, C.; ANDRIEUX, C.; BOY, P.; CHAUMEIL, J.C. Gastrointestinal transit of pellets in rats: effect of size and density. Int. J. Pharm., v.180, n.1, p.123-131, 1999.

TULEU, C.; BASIT, A.W.; WADDINGTON, W.A.; ELL, P.J.; NEWTON, J. Colonic delivery of 4-aminosalicylic acid using amylose-ethylcellulose-coated hydroxypropylmethylcellulose capsules. Aliment. Pharmacol. Ther., v.16, p.1771-1779, 2002.

UGWOKE, M.I.; AGU, R.U.; VERBEKE, N.; KINGET, R. Nasal mucoadhesive drug delivery: Background, applications, trends and future perspectives. Adv. Drug Deliv. Rev., v.57, p.1640-1665, 2005. 
VASIR, J.K.; TAMBWEKAR, K.; GARG, S. Bioadhesive microspheres as a controlled drug delivery system. Int. $J$. Pharm., v.255, p.13-32, 2003.

WATTS, P.J.; ILLUM, L. Colonic drug delivery. Drug Dev. Ind. Pharm., v.23, n.9, p.893-913, 1997.

WILDING, I.R. Scintigraphic evaluation of colonic delivery systems. S.T.P. Pharma Sci., v.5, n.1, p.13-18, 1995.

WILDING, I.R. Site-specific drug delivery in the gastrointestinal tract. Crit. Rev. Ther. Drug Carrier Syst., v.17, n.6, p.557-620, 2000.

WILDING, I.R.; COUPE, A.J.; DAVIS, S.S. The role of gamma-scintigraphy in oral drug delivery. Adv. Drug Deliv. Rev., v.46, p.103-124, 2001.
WITTAYA-AREEKUL, S.; KRUENATE, J.; PRAHSARN, C. Preparation and in vitro evaluation of mucoadhesive properties of alginate/chitosan microparticles containing prednisolone. Int. J. Pharm., v.312, p.113-118, 2006

WOODLEY, J. Bioadhesion: new possibilities for drug administration? Clin. Pharmacokinet., v.40, n.2, p.77-84, 2001.

YANG, L.; CHU, J.S.; FIX, J.A. Colon-specific drug delivery: new approaches and in vitro/in vivo evaluation. Int. $J$. Pharm., v.235, p.1-15, 2002.

Recebido para publicação em 03 de julho de 2007 Aceito para publicação em 27 de agosto de 2008 